\title{
A CONSTRUÇÃO DA PAZ E A PAZ HÍBRIDA: UMA PERSPECTIVA SOBRE O AFEGANISTÃO
}

\section{PEACEBUILDING AND THE HYBRID PEACE: A PERSPECTIVE ON AFGHANISTAN}

Devlin Biezus

Mestranda em Ciência Política na Universidade Federal do Paraná (UFPR).

E-mail: devlinbiezus@gmail.com

\begin{abstract}
Resumo
O presente artigo visa examinar os conceitos de construção da paz (peacebuilding) e da paz híbrida. Seu objetivo é analisar de maneira crítica o processo de construção da paz desenvolvido pela Organização das Nações Unidas (ONU) para compreender porque ela é caracterizada como um processo de pacificação liberal e, também, examinar o conceito da paz híbrida. A metodologia utilizada é a revisão bibliográfica da literatura para que sejam expostas as teorias dos temas pesquisados e a análise documental de fontes primárias. De modo a desenvolver a sua análise, o artigo está dividido em três seções. A primeira trata do histórico da Construção da paz no âmbito das Nações Unidas durante e após a Guerra Fria. Na segunda seção será abordado uma análise crítica das técnicas utilizadas na construção da paz e como essas caracterizam uma 'paz liberal'. Com o intuito de compreender como e porque a paz híbrida é considerada uma alternativa à construção da paz liberal, será também analisado seus conceitos teóricos. Em um terceiro momento, será exposto como a construção da paz e técnicas da paz híbrida foram aplicadas ao contexto do Afeganistão após da invasão estadunidense e a remoção do grupo Talibã da condução política central. Palavres Chave: Peacebuilding; Paz híbrida; Afeganistão.
\end{abstract}

\section{Abstract}

This paper aims to examine the concepts of peacebuilding and hybrid peace. Its objective is to analyze, in a critical manner, the peacebuilding process developed by the United Nations (UN) in order to understand why peacebuilding is portrayed as a liberal peace process; also, its objective is to examine the concept of hybrid peace. The methodology used is the bibliography review of the literature that explains the theories from the researched topics and the documental analyses. In order to develop its analysis, the article is composed in three sections. The first section covers the peacebuilding historical on United Nations' framework during and after the Cold War. The second section approaches a critical analysis of the techniques used in peacebuilding, and how it can be typified as 'liberal peace'. With the goal to understand how and why the hybrid peace is considered an alternative to the peacebuilding, its theoretical concepts will also be explored on the second section. In the third section, it will be presented the peacebuilding and the hybrid peace techniques which were applied in the afghan context after the United States and the Taliban group removal from political authority.

Key words: Peacebuilding; hybrid peace; Afghanistan.

\section{INTRODUÇÃO}


As consequências humanitárias, políticas e econômicas da Segunda Guerra Mundial ocasionaram esforços internacionais para a criação de um novo mecanismo de segurança coletiva. Alguns desses mecanismos são as mediações, resoluções legais e a possibilidade de investigar e fornecer recomendações para solucionar disputas, além da criação da Organização das Nações Unidas (ONU) que fornece alternativas pacíficas às resoluções de disputas. (DIEHL, 2008, p 36). Entre esses mecanismos, também reside a possibilidade do Conselho de Segurança das Nações Unidas em estabelecer operações de paz, as quais são formadas por atividades que visam manter a paz e segurança nos países em conflitos ou pósconflitos. Após a Guerra Fria, os conflitos intra-estatais passaram a ser mais recontes do que as tradicionais guerras entre Estados. Por isso, o número de operações de paz empregadas pelas Nações Unidas aumentou, gerando também um aumento de estudos sobre o tema. As pesquisas dentro desse campo de estudos podem estar direcionadas para o âmbito prático - com ênfase nas resoluções de problemas das operações - ou voltadas a uma perspectiva crítica de como essas atividades são conduzidas.

As principais críticas às operações de paz são relativas a natureza de suas atividades e de como o peacebuilding é operacionalizado. Em síntese, o peacebuilding é desenvolvido por meio de atividades que visam reduzir o risco de que um país em situação pós-guerra retroceda ao conflito armado. Para que esse objetivo seja alcançado, o peacebuilding busca criar bases que sustentem o desenvolvimento e uma paz sustentável. Isso se traduz em medidas endereçadas às esferas da sociedade e do Estado, as quais buscam fortalecer a capacidade do Estado em realizar, de maneira eficaz e legítima, suas funções centrais (ORGANIZAÇÃO DAS NAÇÕES UNIDAS, 2008, p. 18). As medidas empregadas no peacebuilding podem envolver funções como o desarmamento, a desmobilização e a reintegração de combatentes; reformas no setor de segurança; assistência para a condução de eleições e apoio para a restauração da autoridade estatal (ORGANIZAÇÃO DAS NAÇÕES UNIDAS, 2008, p. 26).

Em suma, as críticas ao peacebuilding argumentam que suas atividades não promovem uma paz duradoura porque estão estruturadas em uma operacionalização de modelo ocidental a respeito do Estado. Devido ao peacebuilding estar relacionado com normas e valores liberais, tais como a democratização, o livre mercado, o Estado de direito e reconstrução econômica, a crítica denomina essas operações de paz como paz liberal (PUGH, 2008, p. 409). O conceito da paz liberal proporciona diversas vertentes críticas à condução do peacebuilding, uma delas é a perspectiva da virada local - que introduz a discussão sobre a paz híbrida.

O conceito da paz híbrida é abordado por meio da relação entre a instituição internacional que conduz o peacebuilding e os atores locais. A definição desse termo é feita por Roger Mac Ginty (2011, p. 72) como a transposição de meios que geram novos tipos de espaços, os quais são desenvolvidos pela interação de agentes internos e externos, criando novos significados às instituições já existentes. Esses 
novos espaços são formados pelos atores locais que resistem, ignoram, reformam ou subvertem o processo de peacebuilding conduzido por uma instituição internacional (MAG GINTY, 2011).

Levando em consideração o contexto apresentado, este artigo analisa as perspectivas críticas sobre as operações de paz - com enfoque nas atividades de peacebuilding - e apresenta como o conceito da paz híbrida está relacionado com tais críticas. A partir da evolução histórica das operações de paz o objetivo é compreender como as críticas se endereçam ao processo de peacebuilding. Para isso, busca-se analisar a natureza dessas críticas e apresentar como a paz híbrida se encaixa dentro dessas perspectivas. Essa proposta de estudo se justifica devido à importância teórica e metodológica do conceito da paz híbrida, uma vez que sua concepção é entendida como uma alternativa prática ao modo que as operações de paz contemporâneas são conduzidas. Portanto, possui um papel proeminente nos estudos críticos sobre o peacebuilding. A metodologia utilizada para desenvolver o objetivo do artigo é a revisão bibliográfica da literatura e a análise documental de fontes primárias.

O artigo argumenta que apesar de a paz híbrida ser compreendida como uma alternativa à paz liberal, existem debates que evidenciam a complexidade de como esse fenômeno se forma e discutem os resultados reais que a paz híbrida pode proporcionar. O artigo está dividido em três seções. A primeira seção aborda a evolução histórica das missões de paz no âmbito das Nações Unidas. Apresentam-se as principais diferenças entre as missões denominadas como peacekeeping tradicional e o peacebuilding, além de explicar a conexão entre a ampliação das atividades operacionalizadas nas operações da paz e o entendimento das Nações Unidas sobre a paz e as novas ameaças do cenário internacional no pós-Guerra Fria.

Na segunda seção, as críticas ao peacebuilding e às missões de paz são analisadas. Aqui, apresentase o conceito da paz liberal utilizado pela crítica que busca evidenciar o caráter da universalização dos valores liberais e democráticos empregados nas operações de paz que são conduzidos pelas Nações Unidas. Além disso, a teoria da paz híbrida é contextualizada entre as perspectivas críticas abordadas, e sua definição se apresenta como um resultado das interações entre atores externos que conduzem o processo de peacebuilding e atores locais. Para que essa discussão seja feita, as críticas da virada local são analisadas em conjunto com as principais perspectivas sobre o que é o 'local' e como ele se forma.

Por fim, a terceira seção expõe a construção da paz do Afeganistão a partir das lentes analíticas da paz híbrida. A escolha para a apresentação desse caso reside na importância dada ao tema pela literatura, uma vez que se explora o Afeganistão como um caso paradigmático sobre a paz híbrida (MAC GINTY, 2011; JARSTAD; OLSSON, 2012). Sem pretensão de esgotar o tema, visa-se compreender porque o peacebuilding no Afeganistão pode ser visto a partir da teoria da paz híbrida por meio de exemplos de como isso é operacionalizado e quais são as consequências mais evidentes da interação entre atores internacionais e locais na construção da paz no país. 


\section{A EVOLUÇÃO HISTÓRICA DAS MISSÕES DE PAZ}

As operações de paz passaram por diversas transformações desde o início da Guerra Fria até o período atual, deixando-as cada vez mais complexas e também servindo como resposta às demandas críticas sobre suas falhas. A presente seção apresenta as principais mudanças nas atividades das operações de paz, os conceitos vinculados a essas mudanças e os principais instrumentos no âmbito das Nações Unidas que institucionalizam as atividades das operações de paz. O intuito que guiou essas mudanças foi o de criar um ambiente de paz duradoura, por isso, as atividades se expandiram e buscaram atingir diversas esferas da operação de paz.

Durante a Guerra Fria, as operações de paz realizadas no âmbito das Nações Unidas (ONU) buscavam a sustentação da paz depois da declaração de uma trégua ou cessar-fogo de um conflito. Essas operações são denominadas como peacekeeping e seu objetivo é assegurar que conflitos locais não escalassem para os países vizinhos, ou até mesmo para as duas grandes potências do período - Estados Unidos e União Soviética (RYAN, 2000, p. 27). Para evitar o escalonamento de conflitos, as missões de paz visavam criar um ambiente favorável às negociações diplomáticas e às resoluções pacíficas. As características abarcadas entre a maioria das operações de peacekeeping eram: 1) a separação das partes combatentes para evitar algum engajamento militar; 2) o apoio e monitoramento para a implementação de um cessar-fogo ou um acordo de paz; 3 ) as forças das operações de paz armadas somente para autodefesa e formadas por tropas fornecidas pelos países membros das Nações Unidas; 4) a criação de medidas para a construção de confiança entre as partes (DIEHL, 2008, p. 44-45; ORGANIZAÇÃO DAS NAÇÕES UNIDAS, 2008, p. 19-21).

Além dessas características, o peacekeeping é operacionalizado de acordo com três prerrogativas: o consentimento das nações que receberiam as operações; a imparcialidade das Nações Unidas entre as partes beligerantes; e o não uso da força pelas tropas nas Nações Unidas (KENKEL, 2013, p. 125-124). Bellamy e Williams (2004, p. 3) denominam essas características como a "santíssima trindade" do peacekeeping tradicional. Essas prerrogativas condiziam com os objetivos das missões, já que o intuito era criar um grau de confiança entre os grupos beligerantes e abrir espaço para o diálogo (BELLAMY; WILLIAMS, 2014, p. 3). Ainda, segundo Blanco (2014, p. 269), a configuração formada por essas prerrogativas pode ser explicada pelos seguintes fatores: a limitação das Nações Unidas para intervir em assuntos internos dos países; a falta da institucionalização das operações de paz na Carta das Nações Unidas; a rejeição de uma mediação por um terceiro país pelas partes beligerantes do conflito; e a lógica bipolar do período - que utilizava as operações de paz como um instrumento para manter a ordem internacional.

Algumas das operações de destaque nesse período foram durante a Crise de Suez, no Egito (1956), a operação no Chipre (1964) e após a invasão israelense no Líbano (1978). A maioria das forças de 
peacekeeping no período da Guerra Fria foram empreendidas no Oriente Médio. Nessa região, Estados Unidos e União Soviética apoiavam diferentes países, o que dificultava a mediação de conflitos por um terceiro país. Dessa forma, o papel de intermediação das Nações Unidas era visto pelas potências como importante componente para o gerenciamento de crises (RYAN, 2000, p. 27). O gerenciamento de crises é o cerne das atividades de peacekeeping, devido a isso, Johan Galtung $(1976$, p. 282) define a abordagem de peacekeeping como dissociativa, porque seu objetivo é promover o distanciamento entre os antagonistas do conflito por meio do patrulhamento de fronteiras, do monitoramento do cessar-fogo e da supervisão da retirada das forças em conflito da área.

As operações de peacekeeping reduziram as chances de uma guerra entre a Turquia e Grécia no Chipre e entre Israel e Síria no Líbano (RYAN, 2000, p. 27). Apesar disso, existem diversas desvantagens nessas operações. Galtung (1976, p. 283) argumenta que o peacekeeping busca reestabelecer o status quo anterior ao início do conflito. Sua crítica é que essa abordagem não pergunta se esse status quo vale a pena ser preservado. Portanto, a intenção de manter a paz se limita a promover a ausência de violência direta e não em modificar estruturas sociais ou políticas que causaram o conflito.

Seguindo uma abordagem similar a de Galtung (1976), as principais críticas em relação às operações de peacekeeping argumentam que elas promovem uma solução de curto prazo e não atingem a raiz dos conflitos (BLANCO, 2014, p. 270). Essa limitação condizia com a interpretação sobre a soberania estatal vigente durante o período da Guerra Fria: os assuntos domésticos deveriam ser tratados como interesse exclusivo do Estado nacional e não deve haver interferência externa nas questões nacionais (KENKEL, 2013, p. 126). A limitação apresentada pelas operações de peacekeeping se adequava com os entendimentos do sistema internacional sobre soberania e não-intervenção. Diante disso, encontra-se a limitação apontada pela crítica ao peacekeeping que se volta para sua incapacidade de atingir as guerras ou conflitos intra-estatais. Esses conflitos eram percebidos pela comunidade internacional como questões internas de cada Estado. Portanto, a intervenção iria contra o princípio da soberania (GALTUNG, 1976, p. 285).

A limitação do peacekeeping em atuar nos conflitos dentro dos Estados foi uma das razões para que as operações de paz sofressem mudanças. As mudanças começaram a surgir a partir do fim da Guerra Fria, o que possibilitou a formação de uma nova estrutura para o sistema internacional. Até 1991, os conflitos intra-estatais eram percebidos por meio da ótica bipolar, portanto, suas causas internas eram inexploradas. Ao fim da estrutura bipolar, surgiram novas percepções de segurança as quais viam ameaças além do âmbito estatal. Temas como a origem dos conflitos civis passaram a ter relevância na agenda internacional (BLANCO, 2014, p. 271). O vácuo deixado pelo embate das duas superpotências permitiu a realização de operações de paz mais expansivas as quais se voltavam não apenas para o gerenciamento de crises, mas também para a causa das guerras internas. 
Os conflitos intra-estatais passaram ser caracterizados pelas dimensões que os originavam. Por exemplo, Mary Kaldor (2005) denominou esses conflitos como 'novas guerras'. Ela os descreveu como conflitos travados entre atores estatais e não-estatais que apresentam uma identidade sectária, sejam elas religiosas, étnicas ou tribais (KALDOR, 2005, p. 493). Nesse sentido, as missões de paz necessitavam de uma natureza multidimensional para que fossem além do simples congelamento do conflito. Por exemplo, missões civis foram adicionadas em conjunto ao contingente militar com o intuito de realizar uma transição política do conflito (KENKEL, 2013, p. 128).

Em 1992, com o intuito de institucionalizar e ampliar as ações das operações de paz, Boutros-Ghali - então Secretário-Geral das Nações Unidas - apresentou o documento denominado como a Agenda para a paz $(A / 47 / 277,1992)$. O argumento central do documento é que para alcançar as origens dos conflitos e das guerras, os esforços das missões de paz devem vir dos mais diversos âmbitos, como dos direitos humanos, das liberdades fundamentais, da economia sustentável, do desenvolvimento social e da eliminação de armamentos de destruição em massa $(A / 47 / 277$, 1992). Segundo o documento:

[...]nesse momento de renovação de oportunidades, os esforços da Organização de construir paz, estabilidade e segurança devem englobar assuntos além das ameaças militares a fim de quebrar os grilhões de conflitos e guerras que têm caracterizado o passado. Mas, conflitos armados hoje, assim como ao longo da história, continuam a trazer medo e horror para a humanidade, requerendo nosso envolvimento urgente para tentarmos prevenir, conter e trazê-los a um fim $(A / 47 / 277,1992){ }^{1}$

Como mencionado no documento, são necessários esforços não apenas para eliminar um conflito, mas também para prevenir e contê-lo. Com esses objetivos delimitados, a Agenda para a Paz (A/47/277, 1992) apresenta as seguintes atividades para alcançá-los: 1) a diplomacia preventiva, cujo propósito é evitar o escalonamento de conflitos e sua disseminação; 2) o peacemaking, que é definido como a resolução de conflitos por meios pacíficos; 3) peacekeeping, executado pela presença de oficiais das Nações Unidas em campo - o que usualmente envolve uma equipe militar, policial e civil; 4) peace enforcement (imposição da paz), que envolve o uso de militares para restaurar a paz no local após a violação do cessarfogo por alguma das partes beligerantes; e 5) peacebuilding, ou construção da paz, ação que promove assistência às estruturas que fortaleceram a paz.

Essas diferentes atividades têm o objetivo de expandir as possibilidades da prevenção do conflito e do processo de paz. Segundo o Departamento de Operações de Manutenção da Paz das Nações Unidas (DPKO), o peacebuilding visa reduzir as chances da reincidência da violência por meio do fortalecimento do gerenciamento de conflito em diversos níveis. É um processo a longo prazo que busca criar as condições necessárias para promover uma paz duradoura. Por isso, as medidas do peacebuilding são direcionadas às

\footnotetext{
${ }^{1}$ Tradução da autora. Original em inglês: "So at this moment of renewed opportunity, the efforts of the Organization to build peace, stability and security must encompass matters beyond military threats in order to break the fetters of strife and warfare that have characterized the past. But armed conflicts today, as they have throughout history, continue to bring fear and horror to humanity, requiring our urgent involvement to try to prevent, contain and bring them to an end." $(A / 47 / 277,1992)$.
} 
questões fundamentais do conflito que afetam a sociedade e o Estado (ORGANIZAÇÃO DAS NAÇÕES UNIDAS, 2008). Nesse sentido, o peacebuilding é conduzido após o término de um conflito e pode atuar em diferentes dimensões com o intuito de criar fundações que promovam e garantam uma paz duradoura (A/47/277, 1992). A Agenda para a Paz exemplifica como isso pode ser alcançado:

[...] por meio de acordos que acabem com conflito civil, os quais podem incluir o desarmamento das partes beligerantes anteriores e a restauração da ordem, a custódia e a possível destruição de armas, o repatriamento de refugiados, apoio em consultas e treinamentos dos profissionais de segurança, monitoramento de eleições, avanço nos esforços para proteger os direitos humanos, reformas ou fortalecimento das instituições governamentais e a promoção do processo formal e informal da participação política. $(A / 47 / 277,1992){ }^{2}$

Como demonstrado, os esforços das missões de paz no âmbito das Nações Unidas deixam de se limitarem à prevenção do conflito e passam a ampliar suas atividades de modo a criar condições políticas, econômicas, sociais e de segurança que promovam uma paz perdurável.

Para melhor exemplificar a natureza dos diversos niveis que o peacebuilding atua, Diehl (2008, p. 8) elenca cinco principais dimensões que caracterizam esse processo. Essas dimensões são denominadas pelos: 1) objetivos do peacebuilding; 2) pelas estratégias das operações; 3) pelo momento em que a operação se inicia; 4) pelo contexto do conflito em que a operação de peacebuilding será empregada.

A primeira dimensão está relacionada com os objetivos do peacebuilding, a qual pode ser sintetizada à prevenção da reincidência do conflito. A segunda dimensão se caracteriza pelas estratégias designadas para cumprir os objetivos da missão de paz. Essa estratégia pode possuir uma natureza menos ampla, em que a prevenção de conflitos ocorre por meio do seu gerenciamento, ou pode apresentar atividades mais abrangentes, como o desarmamento dos grupos conflitantes, destruição de armas e o treinamento da equipe de segurança do local em que a operação ocorre. Segundo Diehl (2008, p. 9), essas estratégias mais abrangentes promovem não apenas o gerenciamento do conflito, mas também sua resolução, visto que elas diminuiriam a recorrência do uso de violência pelas partes em conflito.

A terceira dimensão é a escolha do momento oportuno de iniciar a missão de paz. No peacebuilding, as atividades ocorrem após um acordo de paz, diferentemente do peacekeeping tradicional, o qual ocorre após um cessar-fogo e antes de uma resolução final do conflito (DIEHL, 2008, p. 20). A quarta dimensão apontada pelo autor trata do contexto em que o peacebuilding pode ser empregado, assim, podendo ser conduzido tanto em um contexto de conflito civil ou interestatal, uma vez que Estados vizinhos podem interferir no conflito interno de um Estado. Por fim, a quinta dimensão reside nos atores

\footnotetext{
2 Tradução da autora. Original em inglês: "Through agreements ending civil strife, these may include disarming the previously warring parties and the restoration of order, the custody and possible destruction of weapons, repatriating refugees, advisory and training support for security personnel, monitoring elections, advancing efforts to protect human rights, reforming or strengthening governmental institutions and promoting formal and informal processes of political participation." $(A / 47 / 277,1992)$.
} 
que empregam as ações de peacebuilding. A princípio, atores externos possuem um papel de maior significância dentro das missões de paz. Contudo, atores locais também podem estar incluídos nas etapas das atividades do peacebuilding (DIEHL, 2008, p. 10).

As ações de peacebuilding são um exemplo da expansão nas atividades das operações de paz. Para que essas ações fossem possíveis de serem realizadas, alguns conceitos chaves do peacekeeping tradicional foram revisados: como o uso da força e a indivisibilidade da soberania estatal. Para que o peacebuilding pudesse ser implementado, as missões de paz passaram a contar com uma força militar coercitiva e a possibilidade de realizar operações sem o consentimento do país ocupado. Essas mudanças são apresentadas no Relatório Brahimi, desenvolvido no ano 2000 (A/55/305, 2000).

O objetivo do Relatório Brahimi é trazer melhorias para as operações da paz (A/55/305, 2000). Por isso, o relatório é formado por recomendações baseadas em revisões de missões prévias conduzidas pelas Nações Unidas. Segundo o relatório $(A / 55 / 305,2000)$, para que as operações sejam conduzidas de maneira profissional e obtenham sucesso, unidades militares das Nações Unidas devem ser capazes de se defenderem. Gheciu e Paris (2011) argumentam que o papel crescente das forças militares e o crescimento das atividades nas operações de paz proporcionaram um aumento de número dos atores que atuam no peacebuilding. Logo, as operações de paz passaram a contar com a atuação de agências fora do âmbito das Nações Unidas, como a Organização do Tratado do Atlântico Norte (OTAN), a União Europeia e organizações não-governamentais. Além do Relatório Brahimi, o Peacekeeping Operations Principles and Guidelines, denominado como Doutrina Capstone (ORGANIZAÇÃO DAS NAÇÕES UNIDAS, 2008), é um dos principais documentos das Nações Unidas que abordam as diretrizes das operações de paz contemporâneas. Esse relatório visa materializar práticas e princípios empregados nas operações de paz, mas que ainda não haviam sido formalmente institucionalizados.

\section{AS CRÍTICAS AO PEACEBUILDING E O PROJETO DA PAZ HÍBRIDA}

A volta dos conflitos violentos nas missões de construção da paz como no Timor-Leste em 2006, e no Afeganistão, em 2008, fortalece o debate em relação ao peacebuilding. As críticas em relação a esse processo abrangem escopos reformistas, estruturais e da virada local (GOMES, 2013). Desse modo, essa seção apresenta as principais abordagens das críticas ao peacebuilding com enfoque no projeto da paz híbrida.

A literatura crítica sobre as operações de paz contemporâneas questiona a condução desses projetos de modo a apontar suas falhas e limites. As principais críticas se baseiam nos valores carregados intrinsecamente por essas operações. Por exemplo, Michael Pugh (2008) argumenta que as operações de paz são um reflexo da distribuição de poder no sistema internacional, por isso, elas servem para sustentar 
o sistema global ao invés de transformá-lo. Segundo o autor (PUGH, 2008, p. 409), a partir do fim da Guerra Fria, as operações passaram a ser mais abrangentes e baseadas em normas e valores liberais, tais como a democratização, o Estado de direito e reconstrução econômica. Por isso, as críticas ao peacebuilding recaem principalmente à natureza liberal e democrática universalizada pelas missões. Gomes (2013) divide as críticas sobre a construção da paz entre três abordagens: as críticas reformistas, as estruturais e aquelas referentes à virada local.

As críticas reformistas não indagam a natureza das missões de paz por serem calcadas na universalização da democracia liberal, mas na maneira de como a democratização e a liberalização são conduzidas. Gomes (2013, p. 50) ilustra como essa crítica é feita por meio de dois autores: Chesterman (2004; 2007) e Paris (2004; 2010). O argumento de Chesterman (2004; 2007) reside na transição entre as autoridades externas que conduzem as operações para as autoridades locais. Apesar de o autor defender que a prioridade das Nações Unidas ao conduzir o peacebuilding deve ser as eleições do país, ele argumenta que a transição administrativa entre os atores internacionais e o poder local deve ser feita apenas quando o Estado tenha condições em controlar suas instituições. Segundo Chesterman (2007), o meio para realizar essa transição não deve ser feito pelo controle local (local ownership) - que entrega parte das atividades externas à população local para que haja uma participação ativa. Isso porque as autoridades locais careceriam das capacidades institucionais para transforar a estrutura política do país (GOMES, 2013, p. 51).

Em relação a Paris (1997; 2004; 2010), Gomes (2013, p. 50) primeiramente apresenta críticas do autor referentes a universalização do liberalismo. Paris (1997, p. 57) argumenta que o peacebuilding é um experimento de engenharia social que envolve a aplicação de modelos políticos, sociais e econômicos ocidentais em Estados devastados por guerras. O autor afirma que a criação de uma economia capitalista em Estados com instituições fracas apenas aumenta o conflito social, já que a falta dessas instituições faz com que não haja uma estrutura capaz de sanar disputas internas de modo pacífico (PARIS, 1997, p. 57).

Apesar desse posicionamento, Paris (2004) é considerado um crítico reformista. Ele argumenta que a democracia e a economia de mercado são objetivos que promovem a redução de conflitos. Para o autor, o problema das missões de paz não está nos valores liberais democráticos em si, mas em como eles são implementados. A proposta de Paris (2004) é a institucionalização antes da liberalização. Isso significa um maior fortalecimento das instituições dos países ocupados antes da promoção da democratização (GOMES, 2013 p. 53-54).

As críticas estruturais questionam como o peacebuilding contribui para a manutenção da ordem global liberal (GOMES, 2013, p. 55). Segundo Blanco (2017, p. 84), a operacionalização dessa manutenção é feita por meio da normalização dos Estados e populações pós-conflitos. Ao se referir à normalização, o autor utiliza conceitos foucaultianos para ilustrar como essa manutenção ocorre. A normalização é aplicada por meio da disciplina, recompensa e punição dos Estados ocupados pelas operações de paz. Já a 
sociedade desses Estados é normalizada pelo que é chamado de biopolítica: meio de domínio aplicado a vida da população pautado por uma administração calculista da vida em sociedade (BLANCO, 2017, p. 85; GOMES, 2013, p. 58).

Consonante a crítica de Blanco (2017), Michael Pugh (2004; 2008) entende as operações de paz como uma forma de sustentar a distribuição de poder no sistema internacional. Pugh (2004, p. 53) argumenta que a expansão das operações de paz e o caráter humanitário que passou a permeá-las reforça a estrutura do sistema global porque promove a ideologia da boa governança por meio da paz liberal. O autor também aponta para uma contradição nessas missões a qual é formada pela tentativa de manter o capitalismo como um sistema hegemônico por meio das operações de paz e do humanitarismo (PUGH, 2004, p. 53).

Assim como Pugh, David Chandler (2006; 2007; 2010) também é apontado por Gomes (2013, p. 60) como um crítico estruturalista. As críticas de Chandler são direcionadas de maneira mais precisa às práticas de state-building. Segundo Chandler (2007), a reconstrução do Estado é realizada de maneira cientificista e tecnocrata. Isso significa que as operações são guiadas por regras pré-estabelecidas que seguem normas técnicas e administrativas delimitadas pelos atores externos. A consequência disso, segundo o autor, é a falta de consenso popular sobre as instituições reconstruídas, porque não há participação da população local durante o processo decisório. Nesse sentido, a política é utilizada como um instrumento tecnocrata ao invés de ser um meio para a resolução de tensões na sociedade (GOMES, 2013, p. 60). Chandler (2006) argumenta que tal forma de intervenção - que nega à participação popular durante seu processo - é um meio das potências ocidentais exercerem o poder já que esses países não precisam prestar contas para a população local.

De maneira a concordar com a crítica de Chandler, Gomes (2013, p. 60) aponta para um dilema no peacebuilding. Segundo o autor, a forma de como a reconstrução estatal é realizada não deixa espaços para uma autodeterminação local. Portanto, o autor vê a democracia, que é exportada para países pósconflito, como uma panaceia técnica. Isso se dá porque as operações de paz focam nos processos técnicos de implementação de uma política baseada em valores ocidentais e negligencia as forças sociais ao longo desse processo (GOMES, 2013, p. 60-61).

É a partir dessa preocupação com a autodeterminação local que surge a terceira vertente crítica apontada por Gomes (2013). Segundo Gomes (2013, p. 64), a virada local surge como uma crítica ao projeto da paz liberal e de reconstrução estatal e entende a dinâmica local como um dos recursos para que se alcance uma paz perdurável. A virada local enfatiza o papel da sociedade civil, das comunidades locais e dos atores locais no processo de construção da paz, defendendo uma paz que seja formada 'desde baixo' (LEONARDSSON; RUDD, 2015, p. 285). As visões críticas baseadas nesses ideais veem a paz como inerente à população local e argumenta que a comunidade internacional precisa reconhecer tal população 
como um recurso para o peacebuilding e não apenas como receptores dessas missões. Apesar da expansão das atividades das missões de paz, - passando a endereçar não apenas o fim do conflito, mas também a reconstrução pós-bélica - os esforços promovidos no peacebuilding são desenvolvidos em uma estrutura "de cima para baixo" e ainda não veem como prioridade as consequências sociais e humanas (LEONARDSSON; RUDD, 2015, p. 825).

Leonardsson e Rudd (2015) apresentam duas dimensões para explicar como a virada local é entendida pela literatura e instituições internacionais. A primeira dimensão vê o local como um meio de tornar o peacebuilding mais eficaz. A segunda entende o local como um meio de emancipação formado por vozes subalternas. (LEONARDSSON; RUDD, 2015, p. 825). A primeira dimensão referente a virada local é encontrada principalmente no entendimento que as instituições internacionais possuem sobre o tema. Não seria condizente com a realidade afirmar que essas instituições não passaram a abordar o nível local nas missões de peacebuilding. Contudo, seus entendimentos sobre o local se limita à arena subnacional de governança. Por exemplo, as Nações Unidas entendem que a governança local pode servir como atenuador de reivindicações políticas e de poder socioeconômico. Consoante a isso, o Banco Mundial vê a governança local como um meio de aumentar a eficácia da prestação de serviços e promover um diálogo entre cidadãos e representantes governamentais (LEONARDSSON; RUDD, 2015, p. 828).

Nesse sentido, pode-se afirmar que existe uma inserção do local no discurso institucional que conduz o peacebuilding. Contudo, o entendimento das instituições internacionais sobre a apropriação local (local ownserhip) se limita pela interpretação do 'local' como um consultor para a implementação dos modelos políticos e econômicos desenvolvidos externamente (LEONARDSSON; RUDD, 2015, p. 831). Como crítica a essa visão, o African Centre for the Constructive Resolution of Disputes (ACCORD) entende que a apropriação local deve promover a capacidade das sociedades locais em criarem suas próprias instituições sociais e tomar suas próprias decisões sobre as operações de paz (LEONARDSSON; RUDD, 2015, p. 832). Assim, há um embate entre as visões e interpretações sobre qual é o papel do local no peacebuilding: entre um papel de consultor das operações de paz e um papel que busca uma emancipação local.

A segunda dimensão da virada local possui uma perspectiva sobre a emancipação local no processo de peacebuilding. Essa abordagem enfatiza a necessidade de que as vozes subalternas sejam escutadas e critica as agendas dominantes da construção da paz por endereçar a questão local apenas ao nível discursivo. Diferentemente da primeira dimensão, essa entende a apropriação local como uma capacidade das sociedades locais em criar suas próprias instituições sociais e tomar suas próprias decisões sobre as missões de paz. Dessa forma, há uma crítica sobre como a apropriação local é operacionalizada e percebida no discurso de peacebuilding (LEONARDSSON; RUDD, 2015, p. 832). 
Mac Ginty e Richmond (2013) abordam a virada local por uma perspectiva emancipatória. Para os autores, a virada local representa uma oportunidade de modificar ou ampliar a conceitualização e a construção da paz. Isso se dá porque a virada local propõe uma revisão sobre os parâmetros que têm sido utilizados para o entendimento e para a justificativa das intervenções internacionais. Essas novas conceitualizações permitem que conceitos vistos como artificiais e calcados na noção ocidental de soberania estatal sejam superados (MAC GINTY, RICHMOND, 2013, p. 780).

Para exemplificar essa visão, os autores argumentam que as resoluções de conflitos feitas apenas pelas potências ocidentais têm pouca representatividade local do país em conflito. Por isso, critica-se que as tentativas de realização de um acordo de paz são negociadas nas chamadas "bolhas ocidentais". Isso significa que os acordos seguem uma racionalidade ocidental e poucas elites locais provenientes do país em debate são representadas. Como exemplo, cita-se os casos dos acordos no Chipre (1974 e 2004), Israel e Palestina (1992), Bósnia (1995), Kosovo (1998) e Afeganistão (2001) (MAC GINTY, RICHMOND, 2013, p. 764).

Além das elites locais, Mac Ginty e Richmond contextualizam o que forma o local. Segundo eles, o local é formado por diversas agências baseadas localmente e presentes no ambiente de conflito e pósconflito. Algumas agências buscam identificar e criar os processos necessários para paz. Para os autores, essa paz é usualmente caracterizada como emancipatória e voltada ao cotidiano. Isso significa que questões como autoridade, direitos e legitimidade são repensadas e buscam ser refletidas na arquitetura institucional (MAC GINTY; RICHMOND, 2013, p. 769).

Sob as lentes de análise da virada local, os autores procuram entender a paz de uma maneira expansiva e similar a como ela é entendida pela população local. As visões de Mac Ginty e Richmond sobre a paz é pluralista, porque o entendimento sobre paz parte das perspectivas locais, estatais e internacionais. A paz é vista pelos autores como híbrida, múltipla e agonista. Por isso, em todos os níveis - do local ao internacional - existem sujeitos exercendo sua agência a favor, ou contrária à paz (MAC GINTY; RICHMOND, 2013, (p. 764).

O debate sobre a virada local introduz o contexto em que o projeto da paz híbrida está inserido. A conceitualização da paz híbrida é feita por Mac Ginty (2011, p. 72) como a transposição de meios que geram novos tipos de espaços. Esses espaços são desenvolvidos pela interação de agentes internos e externos e criam novos significados às entidades já existentes. Segundo o autor, contextos híbridos são formados por meio do encontro entre a condução impositiva de um processo de peacebuilding e uma resistência local. Assim, o processo de condução da paz liberal passa por modificações ao longo de sua aplicabilidade devido às influências das ações de atores locais. Esses atores seriam capazes de apresentar alternativas à paz liberal seja ignorando, resistindo ou subvertendo esse processo. Isso é definido como uma forma de construção da paz híbrida (MAC GINTY, 2011). 
Segundo Mac Ginty, "o conceito de hibridização nos permite observar o ricochete sofrido pela paz liberal" (2011, p. 11). O autor argumenta que essa reação é capaz de mudar a natureza da paz que está sendo implementada e a identidade dos atores que conduzem a paz liberal. Logo, a paz híbrida emerge das intervenções de paz liberais e é encontrada nos âmbitos políticos, econômicos e sociais. Nesse sentido, o autor afirma que compreender o processo de paz híbrida permite que uma crítica mais sofisticada à paz liberal seja traçada. Isso porque a análise da paz híbrida vai além da noção bidimensional formada pelos atores externos e os atores locais. Essa perspectiva não entende as intervenções liberais como algo estático, mas sim, como processos que estão sujeitos a serem modificados, ou subvertidos, pelas estruturas de poder e normas locais (MAC GINTY, 2011, p. 68). Nesse sentido, a paz híbrida é formada pelo resultado da interação de diversos fatores: 1) a habilidade dos agentes da paz liberal e de suas estruturas em impor o cumprimento de suas vontades; 2) os poderes de incentivo para aplicar as políticas desenvolvidas pelos agentes e estruturas liberais; 3) a habilidade dos atores locais em resistir, ignorar e adaptar às intervenções de paz; 4) a habilidade dos atores, redes e estruturas locais em apresentar e manter formas alternativas de estabelecimento da paz (MAC GINTY, 2011, p. 69).

Por meio da análise dessas interações, segundo o autor, surge uma visão mais complexa dos ambientes das missões de paz contemporâneas (MAC GINTY, 2011, p. 70). Contudo, Mac Ginty (2011, p. 72) aponta algumas ressalvas ao analisar as interações entre agentes internos e externos. O autor enfatiza que ambos os agentes não são entidades puras que se fundem para criar uma terceira entidade híbrida. Esse argumento buscar explicar a diversidade sobre o que forma os agentes locais. Portanto, o que pode ser rotulado como "nativo", na realidade, possui diversas interpretações sobre construção e manutenção da paz. Isso implica em entender as populações locais não como comunidades isoladas e alheias à política global, mas como agentes que também interagem com fatores internacionais.

De maneira similar a Mac Ginty (2011), Oliver Richmond e Audra Mitchell (2012) afirmam que formas únicas de paz surgem quando intervenções liberais de construção da paz colidem com o cotidiano dos atores locais afetados pelo conflito. Os autores também definem a paz híbrida como resultado das mudanças que ocorrem no planejamento do peacebuilding quando esse interage com a realidade do país pós-conflito. Desse modo, Richmond e Mitchell $(2012$, p. 2) buscam identificar as agências locais, as reivindicações por autonomia e as interações dessas esferas locais com a construção da paz liberal para compreender os resultados que surgem dessas relações híbridas. Richmond e Mitchell (2012, p. 34) propõem que as abordagens híbridas de formas de paz podem revelar potencialidades e armadilhas no engajamento do cotidiano nas operações de paz. Por isso, os autores consideram que essas abordagens podem construir formas de paz novas e pós-liberais (RICHMOND; MITCHELL, 2012, p. 35).

Mac Ginty (2011) e Richmond e Mitchell (2012) possuem entendimentos similares sobre a paz pósliberal. Mac Ginty utiliza o termo "paz liberal" apenas porque os atores que a promovem se auto intitulam 
como liberais e utilizam essa retórica justificar suas ações (MAC GINTY, 2011, p. 21). Contudo, o autor argumenta que, na prática, a paz liberal se manifesta de forma não liberal porque ela sofre modificações pelos atores locais ao longo de sua aplicabilidade. Atores locais são capazes de apresentar alternativas à paz liberal, seja ignorando, resistindo ou subvertendo esse projeto (MAC GINTY, 2011, p. 11).

\section{A OPERAÇÃO DE PAZ NO AFEGANISTÃO E A PAZ HÍBRIDA}

Essa seção busca apresentar os principais aspectos da construção da paz conduzida pelas instituições internacionais no Afeganistão e como os atores locais interagem com esse projeto.

O planejamento inicial sobre a reestruturação do Afeganistão foi acordado na Conferência de Bonn, em dezembro de 2001. O Acordo - denominado como Bonn Agreement (S/2001/1154) - foi assinado pelos membros da comunidade internacional e líderes afegãos. Ele estabeleceu quais seriam as autoridades interinas do país após a invasão estadunidense e instituiu a missão da Força Internacional de Assistência para Segurança (ISAF) no Afeganistão. A autoridade interina criada pelo Acordo de Bonn (S/2001/1154, p. 3) era formada pelo corpo administrativo, uma comissão independente espacial para a convocação de uma Loya Jirga emergencial e uma Suprema Corte. A Loya Jirga - ou Grande Conselho - é uma antiga instituição afegã para as resoluções de conflitos e reúne anciões de diferentes etnias e tribos e líderes religiosos. O intuito do Acordo de Bonn ao convocar uma Loya Jirga era estabelecer uma administração mais representativa. Assim, a Loya Jirga apontou Hamid Karzai como presidente do Afeganistão e noventa e seis ministros e deputados, além dos demais membros que formariam a Autoridade Transicional do país - autoridades que ficariam no poder até a realização de eleições (WARDAK; HAMIDZADA, 2012, p. 80).

Nesse sentido, o Acordo de Bonn foi o responsável pela estrutura da transição política do Afeganistão e pelo desenho central do peacebuilding. Esse desenho é formado por cinco principais pilares: 1) a estrutura de um governo interino com um cronograma para sua transição; 2) a reconstrução da capacidade estatal ao nível central, com financiamento estrangeiro imediato para os salários dos funcionários governamentais; 3) apoio financeiro internacional em grande escala para questões humanitárias e a reconstrução do Estado; 4) uma leve presença internacional, com uma missão das Nações Unidas apenas para dar assistência à administração de transição afegã e uma força internacional de manutenção limitada apenas em Cabul; 5) A ONU, ao invés dos Estados Unidos, iria formalmente liderar o apoio internacional durante a transição política (SUHRKE; HARPVIKEN; STRAND, 2004, p. 3). Essa estrutura se apoiava em princípios norteadores como a democracia, a economia de mercado e a soberania das autoridades de transição durante o projeto de reconstrução. O último principio implica que o governo afegão seria responsável pela transição política. Portanto, não foi instalado uma administração internacional comandada pelas Nações Unidas, como havia acontecido no Timor-Leste e no Kosovo (SUHRKE; HARPVIKEN; STRAND, 2004, p. 3). 
Três principais críticas podem ser destacadas a partir da estrutura proposta no Acordo de Bonn. Primeiro, o acordo ignorou a situação pós-guerra que ainda se desenvolvia no Afeganistão com conflitos ainda presentes no interior do país. Segundo, apenas as partes vitoriosas dos conflitos foram chamadas para a negociação do acordo. Por isso, o Talibã foi deixado à parte das negociações em conjunto com as populações associadas ao grupo. Por fim, o acordo não cobria questões que normalmente são determinadas em acordos de paz, como a maneira que seria conduzida desmobilização das milícias e a reconstrução de um novo exército (SUHRKE; HARPVIKEN; STRAND, 2004, p. 4).

Apesar dos esforços do Acordo de Bonn em legitimar o governo interino e o governo de transição por meio das instituições tradicionais, - como a Loya Jirga - o Afeganistão foi visto como fantoche das forças estrangeiras, uma vez que os Estados Unidos escolheram Hamid Karzai para ocupar o cargo presidencial. A questão da legitimidade governamental também foi acentuada pela escolha dos membros de gabinete, já que Karzai priorizou os membros da facção Aliança do Norte - considerada a vencedora na guerra contra o Talibã - o que criou um sentimento de exclusão entre os demais clãs (SUHRKE; HARPVIKEN; STRAND, 2004, p. 4).

Em 2003, a questão de segurança no país começou a se deteriorar devido às insurgências do grupo Talibã. Por isso, a OTAN passou a comandar a missão ISAF. A partir disso, a participação ativa dos Estados Unidos também aumentou (SUHRKE; HARPVIKEN; STRAND, 2004, p. 6). A OTAN liderou a ISAF a partir de 2003, sendo finalizada em 2014. A Organização foi autorizada pelo Conselho de Segurança das Nações Unidas para atuar no Afeganistão e o objetivo central da ISAF foi desenvolver novas forças de segurança afegãs e capacitar o governo do Afeganistão em fornecer uma segurança eficaz em todo o país (OTAN, 2015). A partir de 2011, a responsabilidade sobre o âmbito da segurança foi gradualmente transferida para as forças afegãs. Ao fim de 2014, a transferência foi concluída e a ISAF foi substituída pela missão Resolute Support, de menor tamanho, cujos objetivos são fornecer assistência e treinamento às forças de segurança do Afeganistão. Em seu auge, a ISAF contou com uma força formada por mais de 130 mil pessoas e 51 nações como parceiras. No início da missão suas forças eram direcionadas para a segurança da capital Cabul e a partir de 2006, a missão se expandiu para todo o país (OTAN, 2015).

Devido ao reaparecimento de ataques do grupo extremista Talibã, os esforços de peacebuilding da OTAN se delimitaram principalmente na área militar e policial. Um aspecto chave dessa política foi o desarmamento, a desmobilização e a reintegração de grupos armados não-estatais (FRITZ, 2011, p. 2). Essa abordagem desenvolvida pela OTAN e financiada principalmente pelos Estados Unidos foi alvo de críticas. Um dos argumentos é que a força afegã treinada pela organização internacional não trazia proteção no cotidiano da população, já que o foco da proteção era no governo (FRITZ, 2011, p. 5). Outra crítica direcionada a essa política é em relação à dependência criada entre as forças do Afeganistão e os 
fundos financeiros proporcionados por Estados e demais entidades internacionais, como o Banco Mundial e o Fundo Monetário Internacional (FMI) (SUHRKE, 2009, p. 227).

A teoria da paz híbrida pode ser utilizada como uma lente analítica para entender o processo de peacebuilding no Afeganistão por meio da dinâmica formada entre as elites nacionais afegãs e as elites internacionais, como as Nações Unidas, a OTAN e as instituições financeiras internacionais (MAC GINTY; SANGHERA, 2012). A democratização e o setor de segurança são exemplos de áreas que podem ser analisadas por meio da lente híbrida. O objetivo dessa análise é demonstrar como os atores locais interagem com as normas conduzidas pelos atores internacionais e quais são as consequências dessa interação para a construção da paz. Dessa forma, busca-se problematizar a paz híbrida dentro do contexto afegão.

A democratização do Afeganistão é analisada por Gomes (2018) como um processo híbrido. O autor associa as literaturas dos estudos eleitorais e da teoria da paz híbrida com o intuito de analisar as dinâmicas da competição política (GOMES, 2018, p. 4). Por isso, analisa-se o impacto que o desenho constitucional das eleições afegãs exerce sobre a política do país, a elite política e o eleitorado. A teoria híbrida, segundo o autor, possibilita visualizar a conexão das práticas sociais em contado com as particularidades eleitorais do país. Além disso, essa lente analítica também fornece três principais vantagens para o caso em estudo: 1) fornece ferramentas para a observação de novos espaços de competição que surgem a partir de como os atores internacionais, os atores locais, e as elites nacionais subvertem a estrutura institucional; 2) não enfatiza exclusivamente o peso das regras eleitorais porque busca compreender as práticas de resistência não democráticas; 3) considera as formas negativas produzidas pela democracia híbrida (GOMES, 2018, p. 5).

Gomes (2018, p. 5-6) operacionaliza sua análise por meio de três eixos principais: os aspectos institucionais do sistema eleitoral do Afeganistão; as interações entre as regras eleitorais e as elites locais; e a avaliação do jogo político que ocorre dentro do parlamento. $O$ argumento do autor é que a interação entre o sistema eleitoral, estabelecido por atores internacionais, fornece incentivos institucionais para a fragmentação partidária e para o voto personalista, além de ajudar a compreender a resistência de práticas não democrática e a fragilidade da democracia do Afeganistão (GOMES, 2018, p. 2). Em relação aos aspectos do sistema eleitoral afegão, Gomes (2018, p. 6) aponta que a constituição e as leis eleitorais que foram institucionalizadas pelo Acordo de Bonn favorecem o fortalecimento da autoridade presidencial e enfraquecem os partidos políticos.

O início da democratização do Afeganistão foi fortemente internacionalizado por meio do Acordo de Bonn, o qual foi coordenado pelas Nações Unidas e contava com o apoio formal do governo dos Estados Unidos (SUHRKE, 2008, p. 634). As políticas organizadas pelos atores internacionais impactaram tanto a população afegã quanto o Estado do Afeganistão. Por exemplo, a presença de consultores internacionais 
no país criou um ambiente de desconfiança entre a população afegã que via na diferença salarial entre a equipe internacional e os trabalhadores locais uma discrepância no projeto de democratização. Em relação ao Estado do Afeganistão, sua relação intrínseca com instituições internacionais resultou em uma dependência financeira, onde os recursos financeiros eram direcionados de acordo com a decisão estrangeira. Tendo como exemplo, os Estados Unidos canalizavam seus recursos para as milícias que continuavam a luta contra o Talibã e também controlavam os recursos doados ao Exército Nacional Afegão (SUHRKE, 2008, p. 635).

Além da forte presença de consultores no país e da dependência financeira dos recursos internacionais, a internacionalização também está presente na institucionalização das leis eleitorais do Afeganistão. Os Estados Unidos, por meio de seu embaixador Zalmay Khalilzad, pressionaram as Nações Unidas para que a seleção dos representantes do parlamente fosse baseada no Voto Único Intransferível (GOMES, 2008, p. 6). O sistema de Voto Único Intransferivel determina que os eleitores devem escolher candidatos individuais em províncias de representantes múltiplos. O sistema também não prevê uma lista partidária dos candidatos e a filiação à partidos políticos não é permitida (SUHRKE, 2008, p. 640). As principais críticas em relação a esse sistema apontam para a perspectiva individualista da votação, o que resulta em uma abordagem clientelista dos candidatos para angariar votos (GOMES, 2018, p. 7).

Uma resposta local a esse sistema eleitoral é a votação em bloco, que acontece quando um grupo apoia um único candidato. As principais maneiras que os grupos subvertem as determinações do Voto Único Intransferível são pela determinação do número de candidatos de determinada comunidade iram concorrer às eleições e pela negociação em relação a quem o grupo deve apoiar (GOMES, 2018, p. 8). Gomes (2018, p. 11) aponta que a Câmara dos Deputados do Afeganistão (Wolesi Jirga) também apresenta exemplos do processo democrático híbrido, já que é o local onde as regras institucionais interagem com as práticas sociais. Os principais exemplos são grupos armados que utilizam das eleições democráticas para se legitimarem; os membros do parlamento são intimamente ligados com a província que os elegeram e é esperado que eles forneçam recursos para essas províncias. Essa prática resulta na fragmentação da sociedade e no individualismo, pois as províncias passam a competir para eleger seus candidatos, dessa forma, as situações criadas devido a interação do sistema de Voto Único Intransferível e os atores locais resultam em uma política personalista (GOMES, 2018, p. 12). Como o exemplo citado, a análise por meio da teoria híbrida permite que as dinâmicas entre elites e atores locais sejam observadas (GOMES, 2018, p. 14).

Mac Ginty (2011) demonstra como o contexto híbrido da construção da paz no Afeganistão é desenvolvido na área de segurança. O estudo de caso do autor aponta para a contradição entre o discurso do monopólio da violência pelo Estado central - presente na justificativa em diversas intervenções 
internacionais ${ }^{3}$ - e a cooptação de atores militares não-Estatais afegãos pelo governo apoiado internacionalmente. O objetivo de Mac Ginty (2011) é demonstrar a contradição entre a lógica liberal do peacebuilding e do pragmatismo aplicado em um ambiente de insegurança. Portanto, o foco do estudo é na natureza do sistema que facilitou a cooperação entre diversos atores políticos que é resultado de uma negociação social entre atores locais e externos. A incorporação de comandantes militares não-estatais conhecidos como senhores de guerra - no governo reflete as limitações e contradições da paz liberal. (MAC GINTY, 2011, p. 92). Segundo o autor, a cooptação dos senhores de guerra pelo governo foi institucionalizada pelo Acordo de Bonn devido à rejeição da cláusula sobre o desarmamento voluntário que estava proposta no desenvolvimento do Acordo. Então, ele foi modificado e permitiu-se que as milícias não estatais continuassem com seu arsenal (MAC GINTY, 2011, p. 102).

Três fases podem ser traçadas a partir do papel dos senhores da guerra no Afeganistão pós Talibã: primeiro, há uma cooptação das milícias pelo governo Karzai após o Acordo de Bonn que reflete a dominância desses grupos no campo de combate na guerra contra o Talibã; segundo, há uma tentativa das instituições internacionais e de Karzai em desarmar as milícias paraestatais; terceiro, após 2005, a insurgência do Talibã voltou a ser uma ameaça e os Estados Unidos buscaram nas milícias um aliado contra o grupo terrorista. Essas fases ilustram as tensões e contradições entre a política nacional afegã e as normas propostas pelo peacebuilding liberal (MAC GINTY, 2011, p. 103).

A perspectiva híbrida sobre a segurança no Afeganistão nos permite observar os limites dos poderes dos atores externos e internos, uma vez que nenhum dos atores conseguiu impor sua visão sobre o monopólico coercitivo estatal. O que emergiu entre as normas liberais de construção da paz e a cooptação de milícias paraestatais é um produto entre acordos e negociações entre ideias e práticas internacionais e locais (MAC GINTY, 2011, p. 106). Além da questão do cooptação de paramilitares, o caso do Afeganistão é emblemático para o estudo das relações híbridas porque as categorias sobre o que é externo e o que é local se mesclam. Por exemplo, Mac Ginty (2011, p. 93) questiona se a figura de Hamid Karzai é ocidental ou não-ocidental. Isso porque, apesar de o presidente ser afegão, ele foi escolhido para o cargo devido ao apoio dos Estados Unidos.

A questão da construção da paz híbrida no Afeganistão também é trabalhada por Anna K. Jarstad e Louise Olsson (2012). As autoras utilizam o conceito do local ownership - apropriação local - para compreenderem as interações entre os atores internacionais e locais, bem como as assimetrias dessa relação. Elas afirmam que o resultado de diferentes abordagens de local ownership criaram uma forma de paz híbrida complexa no Afeganistão, onde atores internacionais se interconectam em diversos aspectos do cotidiano (JARSTAD; OLSSON, 2012, p. 105). A problemática proposta pelas autoras é de que existem

\footnotetext{
3 Forças rebeldes e não-estatais foram desmanteladas com a ajuda internacional em países como África do Sul, Irlanda do Norte, Serra Leoa e Líbano (MAC GINTY, 2011, p. 96)
} 
diversos papéis e perspectivas internacionais sobre o local ownership no Afeganistão. Como consequência, cada ator internacional tem suas próprias prerrogativas na escolha dos atores locais que apoiarão sua missão. Essa problemática é necessária pois, permite que observemos a perspectiva dos atores internacionais em relação a quem deve ser o local ownership, qual será o objeto de envolvimento dele e quando esse objeto será passado do controle internacional para o controle local (JARSTAD; OLSSON, 2012, p. 107).

A discussão promovida por Jarstad e Olsson (2012, p. 106) nos permite ver de maneira crítica como o local é apoiado por atores internacionais. A escolha do local que irá representar as instituições internacionais é feita de acordo com a percepção de que um ator local específico pode ser apropriado para conduzir as políticas propostas pelos agentes externos. No Afeganistão, a escolha do local para conduzir as ideias da comunidade internacional fica evidente em diversas situações ao longo da invasão estadunidense e da condução do peacebuilding. Por exemplo, durante a operação Enduring Freedom, os Estados Unidos fizeram do grupo Aliança do Norte como seus aliados. Isso porque ambos tinham como objetivo o desmantelamento do Talibã no país (JARSTAD; OLSSON, 2012, p. 107).

As perspectivas demostradas nessa seção analisam a democratização e a segurança por meio da interação do que é conduzido pelas instituições internacionais e da reação dos atores locais. A teoria híbrida permite a observação dessa dinâmica e a percepção do seu resultado, o qual pode ser, ou não, positivo para a construção de um ambiente de paz duradoura. Além disso, Jarstad e Olsson (2012) trazem uma visão crítica sobre como o 'local' é percebido perante as instituições internacionais. O que permite analisar se a apropriação local é realizada de forma emancipatória, ou apenas para cooptação dos atores locais pelos atores externos.

\section{CONSIDERAÇÕES FINAIS}

Com o início na contextualização histórica sobre as missões de paz no âmbito das Nações Unidas, o artigo analisou como a ampliação das atividades conduzidas por essas missões deram origem ao que atualmente é dominado como peacebuilding. Nessa evolução, considera-se o entendimento das Nações Unidas sobre a paz, o qual passa de uma concepção de fim dos conflitos violentos para a promoção de um ambiente que torna a paz duradoura.

À medida que as operações de peacebuilding foram introduzidas nos cenários pós-conflitos, críticas sobre como isso é operacionalizado surgiram. Nesse sentido, argumenta-se sobre a natureza das atividades que formam o peacebuilding, principalmente a promoção da democracia por meio de eleições e a abertura econômica a partir da liberalização do mercado interno. As críticas a condução do peacebuilding 
são apresentadas de acordo com suas principais características. Assim, três principais vertentes se destacam: 1) as críticas reformistas; 2) as estruturais; e 3) as críticas da virada local.

As críticas da virada local são um ponto de partida para a compreensão da ideia da paz híbrida. Dessa forma, busca-se a definição sobre a paz híbrida a partir da interação entre os agentes externos que conduzem o peacebuilding e os atores locais. A paz híbrida surge como crítica ao peacebuilding porque sua proposta é dar voz e emancipar a população local. Para que isso aconteça, a população local não pode ser vista de modo romântico ou exótico. Assim, analisar como o local se comporta em relação ao peacebuilding - seja o apoiando, modificando ou rejeitando - auxilia no entendimento dos objetivos e das reivindicações dessa população. Conforme apresentado, a paz pós-liberal, ou híbrida, surge a partir das modificações sofridas pelas atividades conduzidas pelos agentes externos ao interagirem com o local. O Afeganistão é usado como exemplo para elucidar como isso ocorre.

O Afeganistão é um exemplo importante na teoria da paz híbrida porque as instituições internacionais tentaram legitimar a construção da paz no país por meio da formação de um governo de transição afegão. Nesse sentido, não foram as Nações Unidas, ou a OTAN diretamente responsáveis por governar o Afeganistão. Apesar do uso de instituições tradicionais do país, o presidente escolhido para governar o país no período de transição foi a figura apontada pelos Estados Unidos. Assim, há uma perspectiva sobre os atores locais na construção da paz no Afeganistão, pois seu objetivo não é emancipatório, mas sim, legitimar as políticas ocidentais para o país.

* Artigo recebido em 02 set 2018, aprovado em 16 set 2018.

\section{REFERENCIAS}

ACCORD. Creating an Enabling Peacebuilding Environment: How Can External Actors Contribute to Resilience? 2014. Disponivel em<http://www.accord.org.za/publication/creating-an-enablingpeacebuilding-environment/> Acesso em: 24 jul. 2018

BELLAMY, A. J.; WILLIAMS, P. Introduction: Thinking anew about peace operations. International Peacekeeping, v. 11, n. 1, p. 1-15, 2004.

BLANCO, R. Del Mantenimiento de la Paz al Proceso de Formación del Estado: un esbozo de los esfuerzos de la ONU para la paz internacional. Foro Internacional, v. LIV, n. 2, p. 266-318, 2014.

. Normalizando anormais na sociedade internacional: Operações de paz, Foucault e a Escola Inglesa. Relações Internacionais, n. 53, p. 83-107, 2017.

CHANDLER, D. Empire in Denial: The Politics of State-Building. London: Pluto Press 2006. 
The State-Building dilemma: Good Governance or Democratic Government? In: HEHIR, A. e ROBINSON, N. (Ed.). State-Building: Theory and Practice. New York Routledge, 2007.

. The uncritical critique of liberal peace. Review of International Studies, v. 36, p. 1-19, 2010.

CHESTERMAN, S. You, the people: The United Nations, Transitional Administration, and State-Building. Oxford: Oxford University Press, 2004.

Ownership in theory and in practice: transfer of authority in UN Statebuilding. Journal of Intervention and Statebuilding, v. 1, n. 1, p. 3-26, 2007.

DIEHL, P. F. Peace Operations. Cambridge: Polity Press, 2008.

DOYLE, M. W. Kant, Liberal Legacies, and Foreign Affairs. Philosophy \& Public Affairs, v. 12, n. 3, p. 205$235,1983$.

FRITZ, J. E. U.S. Peacebuilding in Afghanistan. Bilateral workshop with the Osaka School of International Public Policy (OSIPP). Washington, D.C: Institute for Foreign Policy Analysis: 1-13 P. 2011.

GALTUNG, J. An Editorial. Journal of Peace Research v. 1, n. 1, p. 1-4, 1964.

Three Approaches to Peace: Peacekeeping, peacemaking and peacebuilding. Peace, War and Defence, v. 2, p. 282-304, 1976.

GHECIU, A.; PARIS, R. NATO and the Challenge of Sustainable Peacebuilding. Global Governance: A Review of Multilateralism and International Organizations, v. 17, n. 1, p. 75-79, 2011.

GOMES, A. D. T. Da paz liberal à virada local: avaliando a literatura crítica sobre peacebuilding. Monções: Revista de Relações Internacionais da UFGD, Dourados, v. 2, n. 3, p. 46-76, 2013.

. Hybrid democracy: electoral rules and political competition in Afghanistan. Rev. Bras. Polít. Int., v. 61 n. 1, p. 1-17, 2018.

JARSTAD, A. K.; OLSSON, L. Hybrid Peace Ownership in Afghanistan: International Perspectives of Who Owns What and When. Global Governance, v. 18, p. 105-119, 2012.

KALDOR, M. Old Wars, Cold Wars, New Wars, and the War on Terror. . International Politics, v. 42, p. 491498, 2005.

KEMER, T.; PEREIRA, A. E.; BLANCO, R. A construção da paz em um mundo em transformação: o debate e a crítica sobre o conceito de peacebuilding. Rev. Sociol. Polít., v. 24, n. 6o, p. 137-150, 2016.

KENKEL, K. M. Five generations of peace operations. Rev. Bras. Polít. Int, v. 56, n. 1, p. 122-143, 2013.

LEONARDSSON, $H_{. ;}$RUDD, G. The 'local turn' in peacebuilding: a literature review of effective and emancipatory local peacebuilding Third World Quarterly, v. 36, n. 5, p. 825-839, 2015.

MAC GINTY, R. International Peacebuilding and Local Resistance: Hybrid Forms of Peace. New York: Palgrave, 2011.

MAC GINTY, R.; RICHMOND, O. P. The Local Turn in Peace Building: a critical agenda for peace. Third World Quarterly, v. 34, n. 5, p. 763-783, 2013.

MAC GINTY, R.; SANGHERA, G. Hybridity in peacebuilding and development: 
an introduction. Journal of Peacebuilding \& Development v. 7, n. 2, p. 3-8, 2012.

ORGANIZAÇÃO DAS UNIDAS, Conselho de Segurança. An Agenda for Peace (A/47/277) 17 de junho 1992. . A/55/305. ORGANIZAÇÃO DAS UNIDAS, Conselho de Segurança. 2000. . S/2001/1154. ORGANIZAÇÃO DAS UNIDAS, Conselho de Segurança. 2001.

. United Nations Peacekeeping Operations Principles and Guidelines - The Capstone Doctrine. 2008. Disponível em <http://www.un.org/en/peacekeeping/documents/capstone_eng.pdf.> Acesso em: 10 ago. 2018

OTAN. ISAF's mission in Afghanistan (2001-2014) (Archived) 2015. Disponível em: < https://www.nato.int/cps/en/natohq/topics_69366.htm >. Acesso em: 25 jun. 2018

PARIS, R. Peacebuilding and the Limits of Liberal Internationalism. International Security, v. 22, n. 2, p. 5489, 1997.

. Saving Liberal Peacebuilding. Review of International Studies, v. 36, n. 2, p. 337-365, 2010.

. At War's End: Building Peace after Civil Conflict. Cambridge: Cambridge University Press, 2004.

PARIS, R.; SISK, T. D. The dilemmas of statebuilding: confronting the contradictions of postwar peace operations. New York: Routledge 2009.

PUGH, M. Peacekeeping and critical theory. International Peacekeeping, v. 11, n. 1, p. 39-58, 2004.

Peace Operations. In: WILLIAMS, P. D. (Ed.). Security studies: an introduction. New York: Routledge, 2008.

RICHMOND, O. P.; MITCHELL, A. Hybrid Forms of Peace: From Everyday Agency to Post-Liberalism. New York: Palgrave Macmillan, 2012.

RYAN, S. United Nations peacekeeping: A matter of principles? International Peacekeeping, v. 7, n. 1, p. $27-47,2000$.

SUHRKE, A. The dangers of a tight embrace: externally assisted statebuilding in Afghanistan. In: PARIS, R. e SISK, T. D. (Ed.). The dilemmas of statebuilding: confronting the contradictions of postwar peace operations. New York: Routledge, 2009.

Democratizing a dependent state: the case of Afghanistan. Democratization. v. 15,

n. 3, p.630-48, 2008.

SUHRKE, A.; HARPVIKEN, K.; STRAND, A. Conflictual Peacebuilding: Afghanistan Two Years after Bonn Chr. Michelsen Institute Development Studies and Human Rights. Norway. 2004

WARDAK, A.; HAMIDZADA, $\mathrm{H}$. The Search for Legitimate Rule, Justice and a Durable Peace: Hybrid Models of Governance in Afghanistan. Journal of Peacebuilding \& Development, v. 7, n. 2, p. 79-88, 2012. 